\title{
Macrocyclic polyamine as a selective modifier in a bonded-phase capillary column for the electrophoretic separation of aromatic acids
}

\author{
Wei-Hsi Chen, Chuen-Ying Liu* \\ Department of Chemistry, National Taiwan University, Taipei, Taiwan
}

Received 4 January 1999; received in revised form 25 March 1999; accepted 26 March 1999

\begin{abstract}
The use of a macrocyclic polyamine, 28 [ane]- $\mathrm{N}_{6} \mathrm{O}_{2}$, as a selective modifier in a bonded-phase capillary column for the electrophoretic separation of 14 aromatic acids is described. Parameters that affect the performance of the separations, such as the type of buffer, the $\mathrm{pH}$ and concentration of buffer, the applied potential and the injection mode were studied. By changing the buffer $\mathrm{pH}(4.0-5.0)$, buffer concentration $(10-50 \mathrm{mM})$ and applied potential $(-10 \sim-20 \mathrm{kV})$, optimum conditions were obtained at $-20 \mathrm{kV}$, using an acetate buffer $(20 \mathrm{mM}, \mathrm{pH} 4.5)$, hydrodynamic injection with a vacuum at the buffer reservoir on the detector side and detection at $220 \mathrm{~nm}$. The results showed that the separation was effective under these conditions. The plate number was greater than $4 \cdot 10^{4} \mathrm{~m}^{-1}$. Due to the wide variation in the mobilities of the test compounds, injection studies suggested that a vacuum at the buffer reservoir on the detector side would produce a result that is more representative of the initial sample composition. Benzoic acid in soy sauce, salicylic acid in Salic ointment and Aspirin were sampled and analyzed using the established conditions. (c) 1999 Elsevier Science B.V. All rights reserved.
\end{abstract}

Keywords: Buffer composition; Food analysis; Pharmaceutical analysis; Acids, aromatic; Organic acids; Polyamines

\section{Introduction}

Aromatic organic acids are important compounds in commerce, pharmaceutics, biochemistry and the environment. They are most commonly analyzed by ion chromatography (IC) and ion-exclusion chromatography [1]. As an alternative, several approaches based on reversed-phase chromatography have been used for such separations. However, the columns used were expensive and would only last for up to a few thousand injections. The other disadvantage is the need for long run times and large volumes of eluents. In recent years, capillary electrophoresis has emerged as an increasingly powerful separation tool

\footnotetext{
*Corresponding author.
}

that complements high-performance liquid chromatography (HPLC) and IC. Much research and many applications concerning aromatic organic acid analysis have been reported in the literature. However, in the measurement of small molecule carboxylic acids, reversal or suppression of the electroosmotic flow (EOF) is often needed to give successful separations. Attempts to overcome the problems have included the addition of cationic surfactants [2,3], metal ions [4], quaternary ammonium salts for the multipoint ion association [5], separation in a sulfonated-polymer wall-modified open tubular column [6], use of dynamic control of the EOF [7] and the addition of organic solvents [8,9], etc. Methods involving a coating reagent are likely to result in poorer detection limits. 
Capillary electrochromatography (CEC), a microseparation technique that uses electroosmosis instead of pressure-driven flows to transport the solvent and solutes through a capillary column, has become increasingly important in the past few years [10-14]. Both packed columns and open-tubular columns can be used in this system. They each possess unique capabilities, which differ from those of other separation methods, including chromatography. Research on improvement of the column, one of the essential components in these methods, is likely to become an increasingly vigorous area of research in the coming years [15].

Anion coordination is one of the growing areas in supramolecular chemistry. Several classes of anion receptor molecules have been designed by Lehn [16]. $\mathrm{He}$ also reported the complexation of dicarboxylate ions by the macrobicyclic polyammonium receptor molecule as well as the crystal structure of the cryptate supermolecule. Much stronger binding of the terephthalate dianion than the linear dicarboxylate was indicated, due to the chain length, and the electrostatic and hydrophobic effects provided by it [17].

In our previous papers $[18,19]$, the $24-$ and 28 membered macrocyclic polyamines, [24]ane- $\mathrm{N}_{6}$ and [28] ane- $\mathrm{N}_{6} \mathrm{O}_{2}$ were synthesized and evaluated for their use in bonded-phase capillary columns for the electrophoretic separation of organic and inorganic anions. We found that the selectivity of the separation can be attributed to anion complexation, anion exchange and reversal of the EOF provided by the wall-bonded functional groups. The prepared columns are highly promising in electrophoretic separation, and complexation has not been developed extensively for modifying anion selectivity in capillary electrophoresis. In this work, the coordination behavior of [28] ane- $\mathrm{N}_{6} \mathrm{O}_{2}$, bonded to the fused-silica capillary wall, towards aromatic organic acids was studied and the potential of the prepared column for the separation of these acids was evaluated.

\section{Experimental}

\subsection{Apparatus}

A high-voltage power supply with a $30-\mathrm{kV}$ capacity (Model 890-CE, Jasco, Tokyo, Japan), a variable- wavelength UV-Vis detector (Jasco 870-CE) and an integrator (Jasco 807-IT) were employed for capillary electrophoresis. The separations were carried out on a fused-silica capillary columns with an external coating of polyimide (J\&W Scientific, Folsom, CA, USA) and that was chemically modified with a 28membered macrocyclic ligand containing oxygen and nitrogen as donor atoms. The modified capillaries were of $75 \mu \mathrm{m}$ I.D. and the total length of the capillary was $70 \mathrm{~cm}$, with a distance of $50 \mathrm{~cm}$ between the injection end and the detection window. Samples were injected from the negative end and by hydrodynamic mode via a vacuum at the buffer reservoir on the detector side. The detector was set at $220 \mathrm{~nm}$.

\subsection{Reagents and chemicals}

Most chemicals were of analytical reagent grade from Merck (Darmstadt, Germany). Purified water (18 $\mathrm{M} \Omega \mathrm{cm})$ from a Milli-Q water purification system (Millipore, Bedford, MA, USA) was used to prepare all solutions. $\gamma$-Glycidoxypropyltrimethoxysilane was obtained from Aldrich (Milwaukee, WI, USA). All liquid reagents and solvents used in moisture-sensitive reactions were distilled and collected over type $4 \AA$ molecular sieves.

$o$-Phthalic acid, $m$-phthalic acid, $p$-phthalic acid, benzene-1,2,4,5-tetracarboxylic acid (pyromellitic acid), trimellitic acid, 2,6-pyridinedicarboxylic acid, $p$-sulfanilic acid, benzoic acid and mandelic acid were purchased from Merck. Benzyl alcohol, gallic acid, 3-hydroxy-2-naphthoic acid, $p$-hydroxybenzoic acid, $p$-anisic acid and salicylic acid were from Wako (Tokyo, Japan). o-Acetylsalicylic acid was obtained from Lancaster (Lancashire, UK). Aspirin, Salic ointments and soy sauce were obtained from a supermarket. Stock solutions $(0.01 M)$ of the anions investigated were prepared in methanol and were diluted appropriately with pure water prior to use. All solvents and solutions for CEC analysis were filtered through a $0.45-\mu \mathrm{m}$ PTFE membrane (Millipore).

\subsection{Synthesis of 1,15-dioxa-4,8,12,18,22,26- hexaazacyclooctaeicosane ([28]ane- $\mathrm{N}_{6} \mathrm{O}_{2}$ )}

The anion complexone was prepared from 3,3'- 
diaminodipropylamine and triethylamine, according to the methods described by Liu and Chen [19].

\subsection{Coating of capillaries with $\gamma$ - glycidoxypropyltrimethoxysilane}

Fused-silica capillaries $(75 \mathrm{~cm} \times 75 \mu \mathrm{m}$ I.D.) were first flushed with $1 M \mathrm{NaOH}$ (30 min), then with pure water $(15 \mathrm{~min}), 1 \mathrm{M} \mathrm{HCl}(30 \mathrm{~min})$ and pure water $(15 \mathrm{~min})$. The capillaries were purged with nitrogen for $20 \mathrm{~min}$ before being dried at $110^{\circ} \mathrm{C}$ overnight. For coating, the capillary was filled with a $10 \%(\mathrm{w} / \mathrm{v})$ solution of $\gamma$-glycidoxypropyltrimethoxysilane in toluene. The capillary was kept for $3 \mathrm{~h}$ at $110^{\circ} \mathrm{C}$, for silylization. After purging with toluene to remove unreacted reagent for several minutes, the capillaries were dried in a vacuum oven. The capillary was then filled with a $1 \%(\mathrm{w} / \mathrm{v})$ solution of the macrocyclic compound, [28]ane$\mathrm{N}_{6} \mathrm{O}_{2} \cdot 6 \mathrm{HCl}$ in $N, N$-dimethylformamide. After standing for $10 \mathrm{~h}$ at $120^{\circ} \mathrm{C}$, for functionalization, the dried capillaries were purged with methanol and pure water for several minutes before being equilibrated with buffer solution. They were then ready for use.
Table 1

Chemical and physical properties of the model compounds

\begin{tabular}{lll}
\hline Compound & $\mathrm{p}_{\mathrm{a}}{ }^{\mathrm{a}}\left(25^{\circ} \mathrm{C}, \mu=0\right)$ & Equiv. conduc. $^{\mathrm{b}}$ \\
\hline $\mathrm{I}$ & $1.70,3.12,4.92,6.23 ;(2.25)^{\mathrm{c}}$ & 68.1 \\
II & $2.48,4.04,5.54 ;(1.82)^{\mathrm{c}}$ & 62.7 \\
III & $2.23,5.07 ;(1.21)^{\mathrm{c}}$ & \\
IV & $2.95,5.40 ;(1.10)^{\mathrm{c}}$ & 52.3 \\
V & $3.50,4.50 ;(1.43)^{\mathrm{c}}$ & 54.7 \\
VI & $3.54,4.46 ;(1.45)^{\mathrm{c}}$ & 52.6 \\
VII & $2.97 ;(0.97)^{\mathrm{c}}$ & 36.0 \\
VIII & $3.40 ;(0.93)^{\mathrm{c}}$ & \\
IX & $4.20 ;(0.67)^{\mathrm{c}}$ & 32.4 \\
X & $3.23 ;(0.95)^{\mathrm{c}}$ & \\
XI & $2.54 ;(0.99)^{\mathrm{c}}$ & \\
XII & $4.27 ;(0.63)^{\mathrm{c}}$ & 29.0 \\
XIII & $4.48 ;(0.51)^{\mathrm{c}}$ & 31.4 \\
XIV & $4.58 ;(0.45)^{\mathrm{c}}$ & \\
XV & 3.49 & \\
\hline
\end{tabular}

${ }^{\mathrm{a}}$ From Ref. [29].

${ }^{\mathrm{b}}$ Limiting equivalent ionic conductance $\left(\mathrm{S} \mathrm{cm}^{2}\right.$ equivalent $\left.{ }^{-1}\right)$ : data from Ref. [30].

${ }^{\mathrm{c}}$ Effective charge at $\mathrm{pH} 4.5$.

\section{Results and discussion}

Initial studies centered on the possible use of the complexone-bonded-phase capillary column for the<smiles>O=C(O)c1cc(C(=O)O)c(C(=O)O)cc1I</smiles>

I<smiles>O=C(O)c1ccc(C(=O)O)cc1</smiles>

VI<smiles>O=C(O)c1cc2ccccc2cc1O</smiles>
XI<smiles>O=C(O)c1ccc(C(=O)O)c(C(=O)O)c1</smiles>

II<smiles>O=C(O)c1ccccc1O</smiles>

VII<smiles>O=C(O)c1cc(O)c(O)c(O)c1</smiles>

XII<smiles>O=C(O)c1ccccc1</smiles>

VIII<smiles>COc1ccc(C(=O)O)cc1</smiles>

XIII<smiles>O=C(O)c1ccccc1C(=O)O</smiles>

IV<smiles>O=C(O)c1ccccc1</smiles>

IX<smiles>O=C(O)c1ccc(O)cc1</smiles>

IVX<smiles>O=C(O)c1cccc(C(=O)O)c1</smiles>

V<smiles>Nc1ccc(O)cc1</smiles>

$\mathbf{X}$

Fig. 1. Structures of the compounds selected. 
separation of aromatic organic acids. Table 1 lists the physical and chemical properties of the selected compounds (the structures are shown in Fig. 1). In order to obtain conditions of high affinity towards the organic anion for the bonded-phase capillary column and a background electrolyte with a matching mobility, two kinds of background electrolyte were investigated.

\subsection{Phosphate buffer}

\subsubsection{Composition of the buffer}

Stable complexes can be formed between bonded phase ligand and organic anions over a wide range of $\mathrm{pH}$ conditions. However, widespread ionic mobility was observed for the analytes, as shown in Table 1. At lower $\mathrm{pH}$ values, the polyamines are more protonated and more stable complexes can be formed with the anions. Hence, a buffer system comprising sodium dihydrogenphosphate (limiting equivalent ionic conductance/S $\mathrm{cm}^{2}$ equivalent ${ }^{-1}, 33$ ) and disodium hydrogenphosphate (limiting equivalent ionic conductance $/ \mathrm{S} \mathrm{cm}^{2}$ equivalent ${ }^{-1}, 57$ ) with a $\mathrm{pH}$ range of 4-7 was chosen. However, using

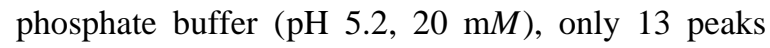
were obtained for the 14 organic acids (Fig. 2). Gallic acid and $p$-anisic acid coeluted, whereas $m$ and $p$-phthalic acid and salicylic acid were not baseline-resolved.

Hence, other parameters that influence the separation efficiency, such as the type of running buffer, $\mathrm{pH}$, concentration, applied potential, sample injection mode, the addition of organic solvents, etc. were studied.

\subsubsection{Type of sample injection}

The influence of both electrokinetic and hydrodynamic injection on the resolution and sensitivity of the determination of the test compounds was studied. The latter was accomplished by either elevating the capillary at the sample end, permitting sample introduction by siphoning, or by applying a vacuum at the buffer reservoir on the detector side. Both the peak height and migration times obtained using these methods for all of the analytes studied are provided in Fig. 3. Since the amount injected using the electrokinetic method is related to ionic mobility, pyromellitic acid moves quickly and its sensitivity is

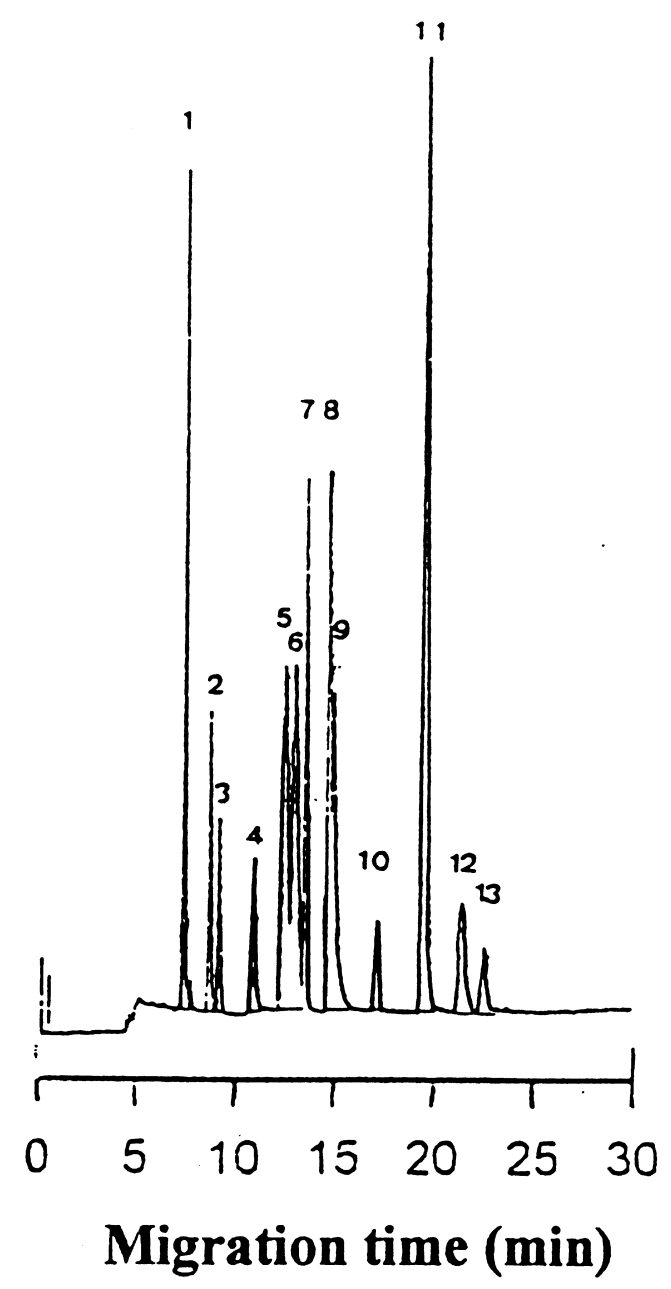

Fig. 2. Electropherogram of aromatic acids. Column: fused-silica capillary $(50 \mathrm{~cm} \times 75 \mu \mathrm{m}$ I.D. $)$ with covalent surface modification using macrocyclic polyamine, [28] ane $-\mathrm{N}_{6} \mathrm{O}_{2}$. Sample injection, $-5 \mathrm{kV}$ for $15 \mathrm{~s}$. Background electrolyte, phosphate buffer (20 $\mathrm{m} M$, pH 5.2). Applied voltage, $-20 \mathrm{kV}$. Detection was at $220 \mathrm{~nm}$. Peaks: 1 , pyromellitic acid $(5 \mu M) ; 2$, trimellitic acid $(5 \mu M) ; 3$, 2,6-pyridine-dicarboxylic acid $(5 \mu M) ; 4, o$-phthalic acid $(5 \mu M)$; $5, m$-phthalic acid $(5 \mu M) ; 6, p$-phthalic acid $(5 \mu M) ; 7$, salicylic acid $(5 \mu M) ; 8$, mandelic acid $(5 \mu M) ; 9, p$-sulfanilic acid (5 $\mu M) ; 10$, benzoic acid $(5 \mu M) ; 11,3$-hydroxy-2-naphthoic acid (5 $\mu M) ; 12$, gallic acid and $p$-anisic acid $(5 \mu M) ; 13, p$-hydroxybenzoic acid $(5 \mu M)$.

the greatest. Because $p$-hydroxybenzoic acid and $p$-anisic acid migrate more slowly than the other analytes, samples injected by electromigration at -5 $\mathrm{kV}$ for $15 \mathrm{~s}$, even at a concentration of $40 \mu M$, still led to poor sensitivity. Hence, the sample injected 


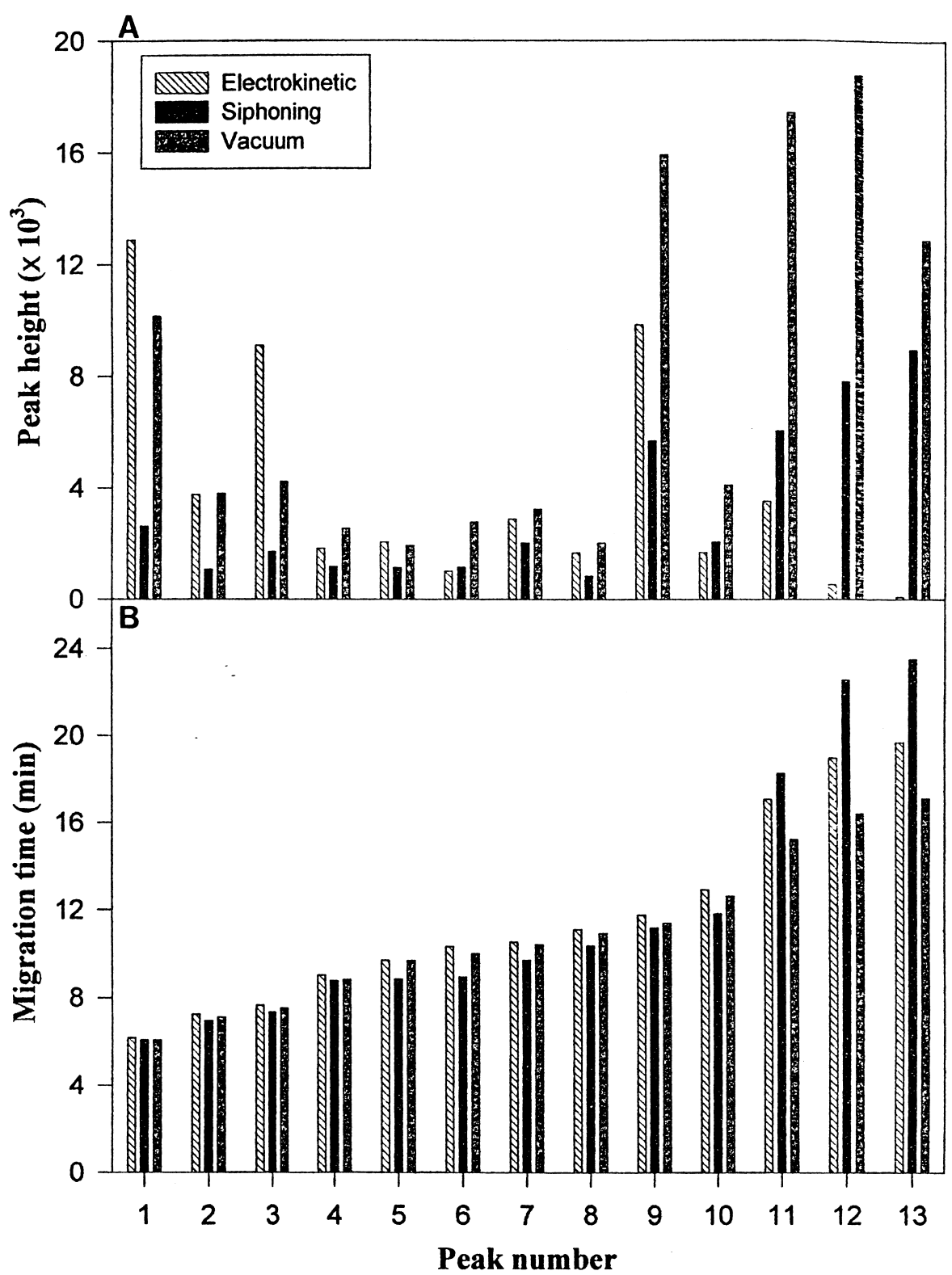

Fig. 3. Peak height and migration times of aromatic acids using various injection modes. Conditions are the same as in Fig. 2 except for the injection mode. Electrokinetic $(-5 \mathrm{kV}, 15 \mathrm{~s})$; siphoning $(15 \mathrm{~cm}, 25 \mathrm{~s})$; vacuum at outlet end (3 ml syringe, $2 \mathrm{~s})$.

into the column does not have the same composition as the original sample. Siphoning by elevating the sample end permitted better quantitative results. However, hydrodynamic injection via a vacuum on the detector side was the best of the three methods. The reason might be due to the greater pressure difference than obtained using the siphoning method. Accordingly, it was adopted for the further study.

\subsubsection{Optimization of the phosphate-methanol buffer}

Stock solutions of all analytes were prepared in 
methanol and diluted with pure water prior to use. Since the composition of the solvent has the potential to influence the mobility of these compounds $[8,9]$, $20 \mathrm{~m} M$ phosphate buffer, $\mathrm{pH}$ 4.9-methanol (95:5, $\mathrm{v} / \mathrm{v})$ was tested for the separation of organic acids. By changing the applied potential, a faster separation was achieved with the higher voltage $(-20 \mathrm{kV})$ (Fig. 4). Decreasing the applied potential gave rise to better resolution. At applied potential of -15 and $-10 \mathrm{kV}, 13$ peaks were baseline-separated, out of the 14 compounds investigated (coelution of gallic acid and $p$-anisic acid). However, peak-broadening was observed for the slower-migrating analytes and some overlapping for the last two peaks occurred at an applied potential of $-10 \mathrm{kV}$.

The effects of varying the methanol concentration over the range of 5-20\% (v/v) were studied (Fig. 5). With increasing methanol concentration, there was a drastic decrease in the mobilities, especially for the slower-migrating analytes, but resolution between most acids improved. At methanol concentrations greater than $10 \%$, the resolution between gallic acid and $p$-anisic acid improved significantly, however, peak-broadening for all peaks was indicated.

Increasing the acidity of the phosphate buffer to $\mathrm{pH} 4.0$, even at $5 \%(\mathrm{v} / \mathrm{v})$ methanol, produced a partial separation of gallic acid and $p$-anisic acid. At $10 \%$ methanol, baseline-separation of these two compounds was obtained. Further increasing the concentration of methanol, however, not only resulted in a poorer separation efficiency for most acids, but the migration time was longer than $1 \mathrm{~h}$ for the elution of gallic acid, $p$-anisic acid and $p$-hydroxybenzoic acid.

\subsection{Acetate buffer}

To improve the separation efficiency, acetate buffer with a limiting equivalent ionic conductance of $40.9 \mathrm{~S} \mathrm{~cm}^{2}$ equivalent ${ }^{-1}$ and a $\mathrm{p} K_{\mathrm{a}}$ of 4.76 was selected for further study.

\subsubsection{Acidity of the acetate buffer}

An increase in buffer $\mathrm{pH}$ from 4.0 to 4.9 causes an obvious increase in the migration time for most analytes, except those compounds of greater ionic mobility (Fig. 6). The results indicate that the bonded ligand does have at least some effect on migration of the solute, since the EOF of the bonded- phase column is reversed compared with that of a bare capillary column and the migration velocity of the neutral marker decreases as the $\mathrm{pH}$ increases [19]. In other words, a greater effective charge would result in a more stable complex with the bonded ligand, although we cannot ignore the factor that the electrophoretic migration velocity of the analytes would be affected by the change in $\mathrm{pH}$. A lower $\mathrm{pH}$ would result in a less ionized solute, which, in turn, would lead to weaker complex formation with the bonded-phase and, hence, a shorter migration time. At $\mathrm{pH} 4.0, p$-anisic acid ( $\left.K_{\mathrm{a}} 4.48\right)$ was eluted after $p$-hydroxybenzoic acid ( $\left.K_{\mathrm{a}} 4.58\right)$, since the effective charges are nearly the same, and the molecular mass of the former is larger. However, at $\mathrm{pH} 4.4$, they eluted, unexpectedly, in reverse order. The significant difference in mobility between $p$-anisic acid and $p$-hydroxybenzoic acid is probably the result of the slightly greater effective charge of $p$-anisic acid than $p$-hydroxybenzoic acid (Table 1). Similar behavior also existed among the other compounds. At $\mathrm{pH}$ 4.0, 3-hydroxy-2-naphthoic acid ( $\mathrm{p} K_{\mathrm{a}}$ 2.54) had a much greater effective charge and eluted far more slowly than benzoic acid $\left(\mathrm{p} K_{\mathrm{a}} 4.20\right)$ and $p$-sulfanilic acid $\left(\mathrm{p} K_{\mathrm{a}} 3.23\right)$. The phenomenon is primarily due to the larger molecular mass of 3hydroxy-2-naphthoic acid compared with benzoic acid (a difference of 66). The higher effective charge of the former may result in the formation of a more stable complex with the bonded ligand and this could be the other reason. However, less diversity was obtained at the higher $\mathrm{pH}$. Increasing the $\mathrm{pH}$ to 4.4 resulted in poor separation of the pair. On further increasing the $\mathrm{pH}$ to 4.9 , the elution order was reversed, as mentioned before, but the difference was not so much. Fig. 7 indicates that the migration time slightly increases for 3-hydroxy-2-naphthoic acid, while that of benzoic acid increases noticeably. We realize that the variation in the effective charge for benzoic acid is more significant than that for 3hydroxy-2-naphthoic acid, as the buffer's $\mathrm{pH}$ was raised. This causes a stronger interaction between the bonded ligand and benzoic acid than before, and the increase even surpassed that of 3-hydroxy-2naphthoic acid.

\subsubsection{Concentration of acetate buffer}

The effect of changing the concentration of the acetate buffer, over the range $10-50 \mathrm{~m} M$, on the 


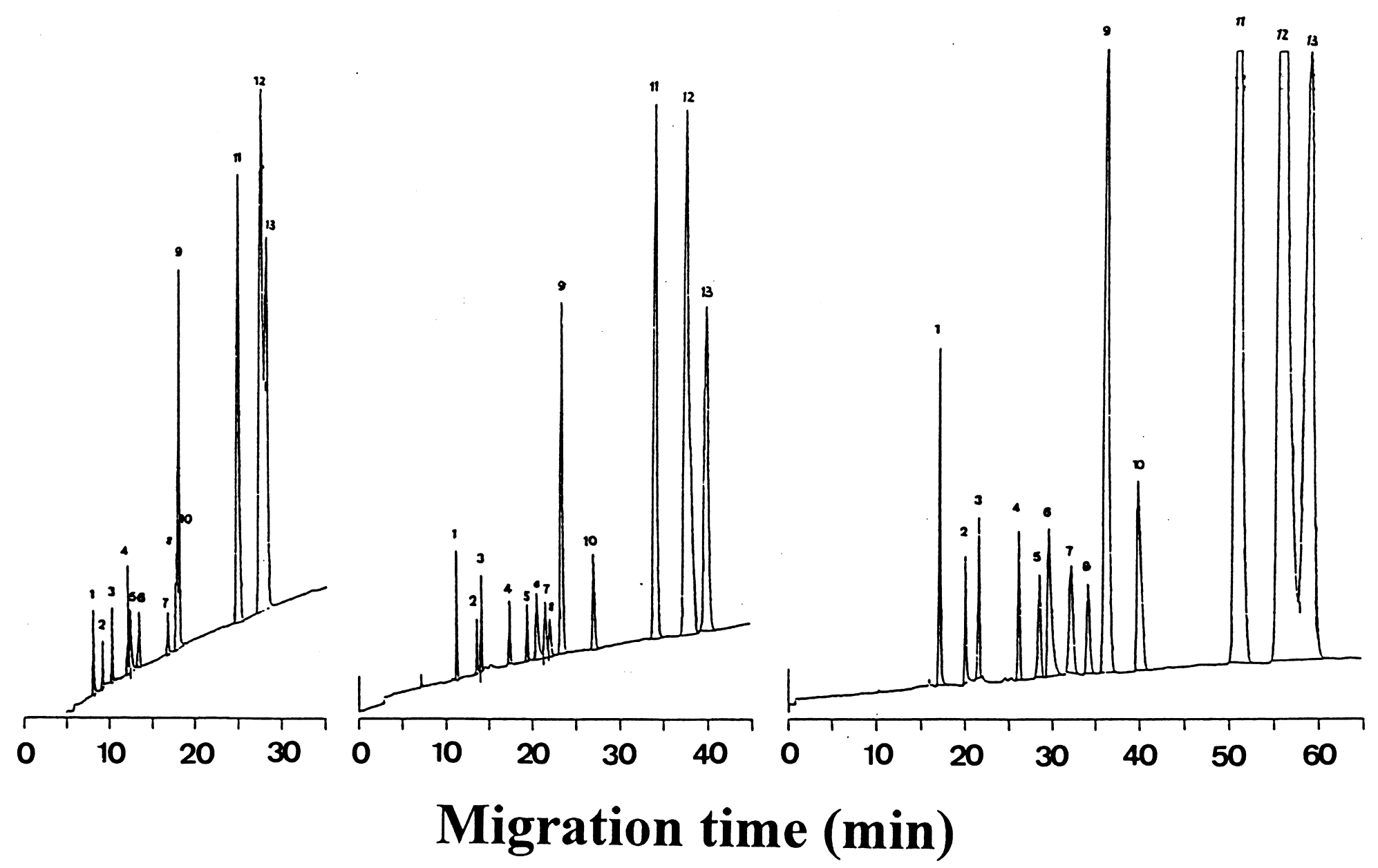

Fig. 4. Electropherograms of the separation of aromatic acids with different applied potentials. Column, fused-silica capillary $(50 \mathrm{~cm} \times 75 \mu \mathrm{m}$ I.D. $)$ with covalent surface modification using macrocyclic polyamine, [28] ane- $\mathrm{N}_{6} \mathrm{O}_{2}$. Sample injection, siphoning $(15 \mathrm{~cm}, 25 \mathrm{~s})$. Background electrolyte, phosphate buffer $(20 \mathrm{~m} M$, pH 4.9$)-$ methanol (95:5, v/v). Detection was at $220 \mathrm{~nm}$. Applied voltage, (A) $-20 \mathrm{kV} ;(\mathrm{B})-15 \mathrm{kV}$; (C) $-10 \mathrm{kV}$. Peaks: 1, pyromellitic acid (5 $\mu M$ ); 2 , trimellitic acid (5 $\mu M$ ); 3 , 2,6-pyridine-dicarboxylic acid $(5 \mu M) ; 4, o$-phthalic acid $(5 \mu M) ; 5, m$-phthalic acid $(10 \mu M) ; 6, p$-phthalic acid $(10 \mu M) ; 7$, salicylic acid $(20 \mu M) ; 8$, mandelic acid $(20 \mu M)$;

9, $p$-sulfanilic acid $(20 \mu M) ; 10$, benzoic acid $(30 \mu M)$; 11, 3-hydroxy-2-naphthoic acid $(5 \mu M) ; 12$, gallic acid and $p$-anisic acid $(40 \mu M)$; $13, p$-hydroxybenzoic acid $(40 \mu M)$. 


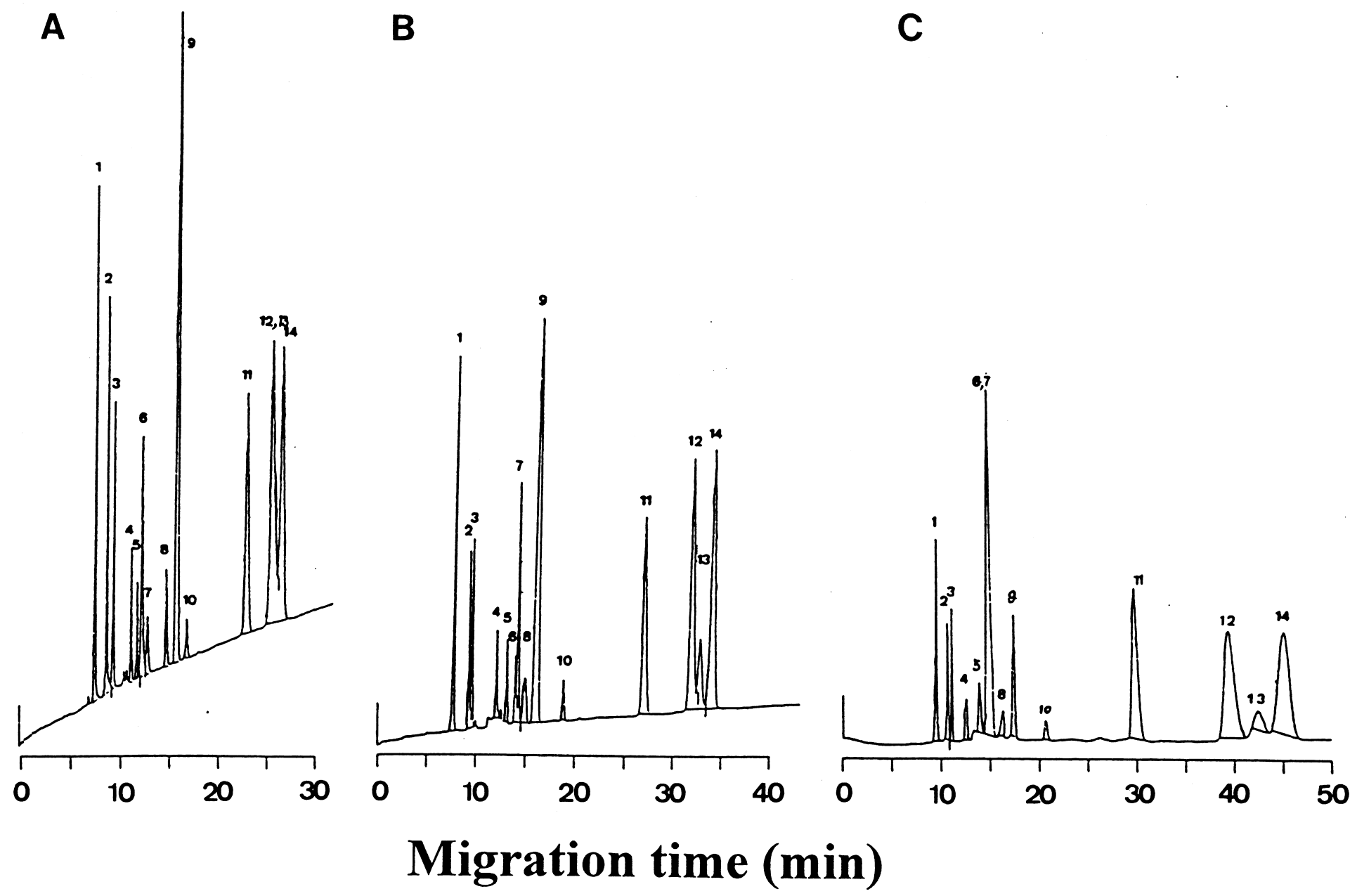

Fig. 5. Electropherograms demonstrating the effect of methanol concentration on the migration of aromatic acids. Conditions were the same as in Fig. 2, except that various amounts of methanol were added to the phosphate buffer $(20 \mathrm{mM}, \mathrm{pH} 4.4)$ and the sample was injected using the vacuum mode ( $3 \mathrm{ml}$ syringe, $3 \mathrm{~s}$ ). Methanol concentration (\%, v/v): (A) 5; (B) 10; (C) 20. Peaks: 1, pyromellitic acid $(5 \mu M)$; 2, trimellitic acid $(5 \mu M) ; 3,2$,6-pyridine-dicarboxylic acid $(5 \mu M) ; 4, o$-phthalic acid $(5 \mu M)$; $5, m$-phthalic acid $(10 \mu M) ; 6, p$-phthalic acid $(10 \mu M) ; 7$, salicylic acid $(10 \mu M) ; 8$, mandelic acid $(10 \mu M) ; 9, p$-sulfanilic acid $(10 \mu M)$; 10, benzoic acid $(10 \mu M) ; 11$, 3-hydroxy-2-naphthoic acid $(2 \mu M) ; 12$, gallic acid $(10 \mu M) ; 13$, $p$-anisic acid $(10 \mu M)$; 14, $p$-hydroxybenzoic acid $(10 \mu M)$. 
A

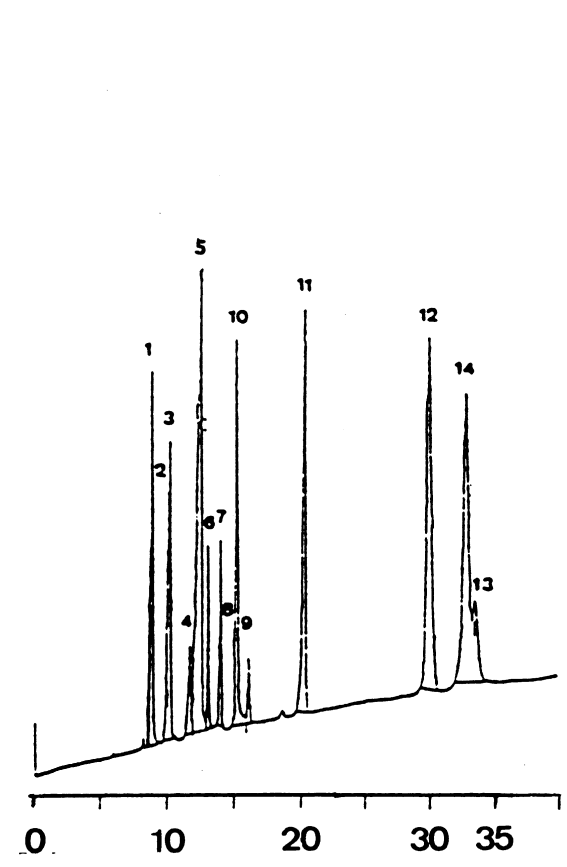

B

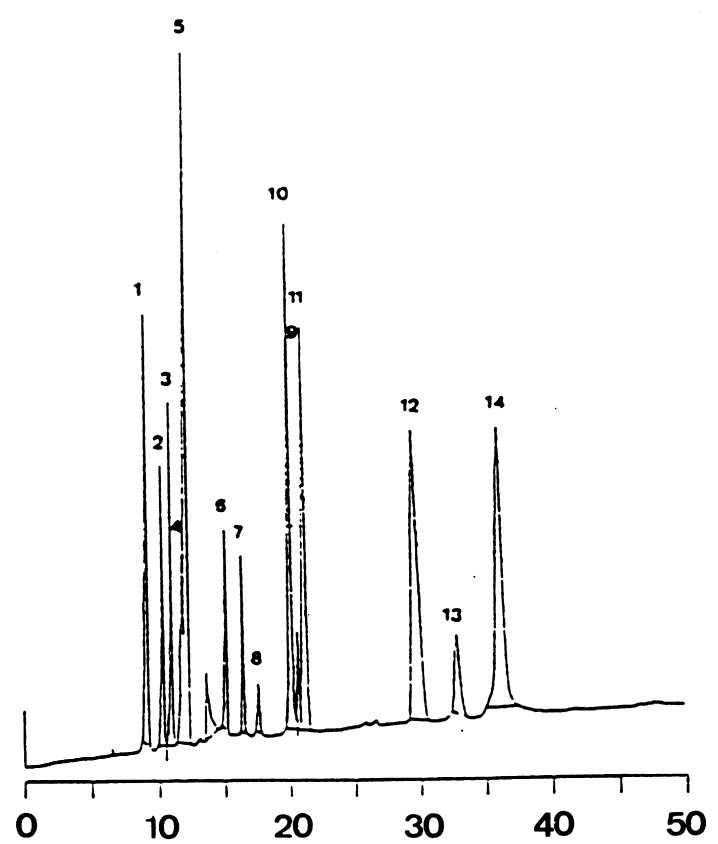

C

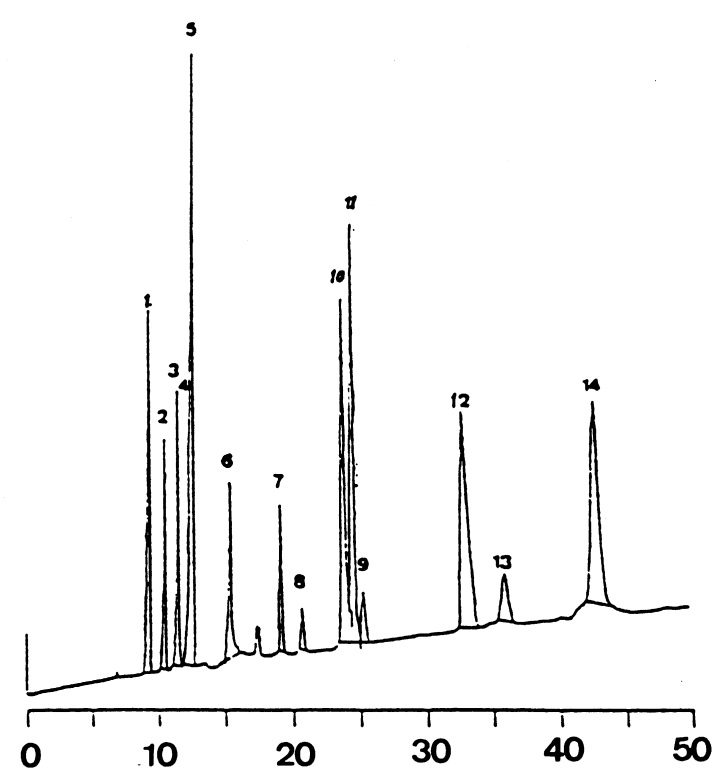

\section{Migration time (min)}

Fig. 6. Electropherograms of the separation of aromatic acids at different $\mathrm{pH}$ values. Conditions were the same as in Fig. 2, except that the background electrolyte was acetate buffer $(20 \mathrm{mM})$ and the sample was injected in the vacuum mode ( $3 \mathrm{ml}$ syringe, $2 \mathrm{~s}$ ). The $\mathrm{pH}$ of the acetate buffer was as follows: (A) pH 4.0; (B) pH 4.4; (C) pH 4.9. Samples: 1, pyromellitic acid $(5 \mu M) ; 2$, trimellitic acid $(5 \mu M) ; 3,2,6$-pyridine-dicarboxylic acid $(5 \mu M) ; 4, o$-phthalic acid $(5 \mu M) ; 5, m$-phthalic acid $(10 \mu M) ; 6, p$-phthalic acid $(10$ $\mu M) ; 7$, salicylic acid $(10 \mu M) ; 8$, mandelic acid $(10 \mu M) ; 9$, $p$-sulfanilic acid $(10 \mu M)$; 10, benzoic acid $(10 \mu M)$; 11, 3-hydroxy-2-naphthoic acid $(2 \mu M)$; 12 , gallic acid (10 $\mu M) ; 13, p$-anisic acid $(10 \mu M) ; 14, p$-hydroxybenzoic acid $(10 \mu M)$. 


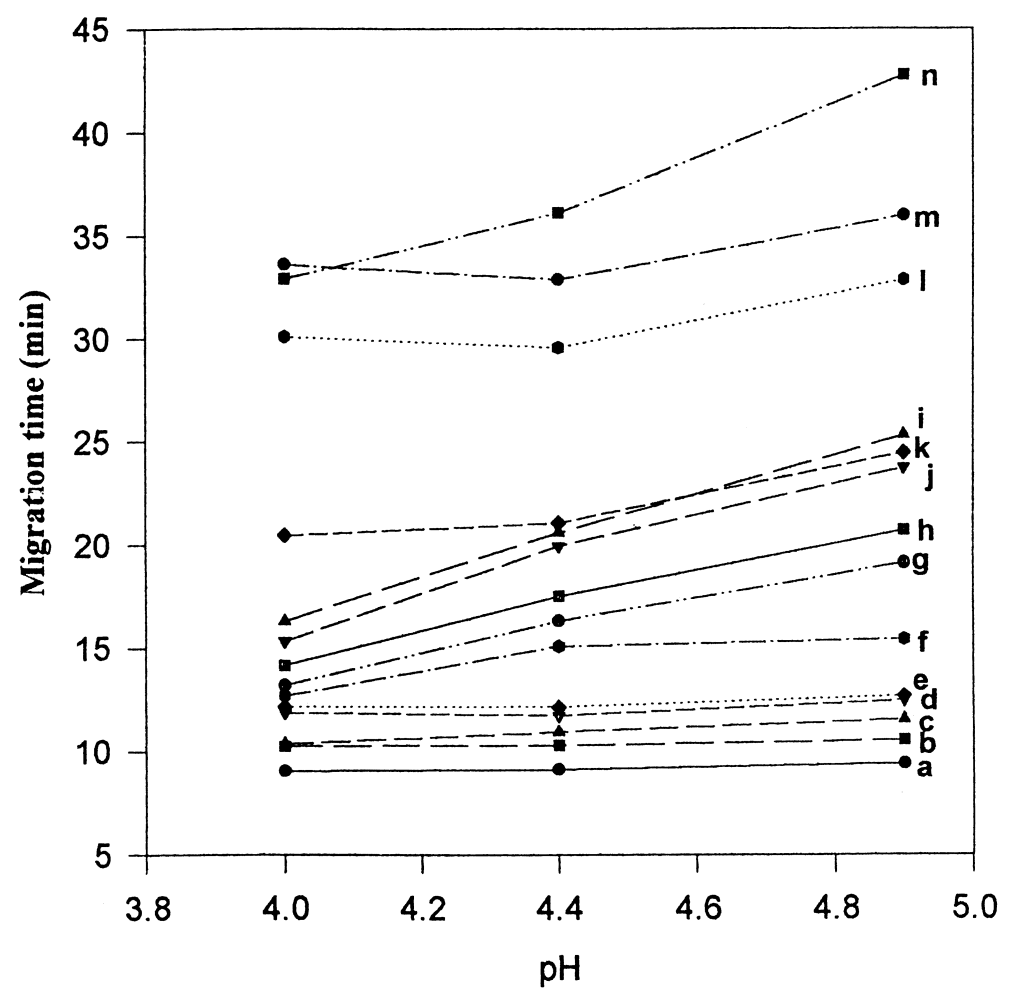

Fig. 7. Effect of the $\mathrm{pH}$ of the acetate buffer on the migration of aromatic acids. Conditions were the same as those given in Fig. 6.

separation was studied. The results indicate that, at lower buffer concentrations $(20 \mathrm{mM})$, baseline resolution is attainable. At higher concentrations, higher sensitivity was provided but the migration was slower.

\subsubsection{Influence of applied potential}

With acetate buffer $(20 \mathrm{mM}, \mathrm{pH} 4.4)$ as the background electrolyte, the effect of applied potential, at $-20,-15$ and $-10 \mathrm{kV}$ was tested (Fig. 8). A faster separation can be achieved with a higher voltage. When operating at lower electric field strength, the separation was slower but similar resolution and migration order were achieved. Therefore, the applied potential of $-20 \mathrm{kV}$ was selected as the best separation condition.

\subsubsection{Addition of metal ions}

The use of a chelating resin for metal binding both in liquid chromatography and gas chromatography results in enhanced selectivity [20-22]. Hence, the effect of the direct addition of metal ions to the background electrolyte on the electrophoretic mobility and the migration behavior of organic acids was studied. Chiari et al. found that the addition of magnesium, calcium, manganese, cobalt and nickel salts, respectively, to a 2-( $N$-morpholino)ethanesulfonic acid (50 $\mathrm{m} M, \mathrm{pH} 5.5)-$ Tris buffer, produced no significant difference except in the case of copper [4]. In this work, the influence of copper and zinc acetate at different concentrations $(0.1-1 \mathrm{mM})$ on transit time and selectivity was investigated. The most significant changes in mobility were caused by the addition of $\mathrm{Cu}(\mathrm{II})$. At a concentration of $0.1 \mathrm{~m} M$, there was an increase in analyte mobility and worse resolution. There might have been the formation of a lower charge copper-carboxylate complex. This results in weaker electrostatic forces between the analyte and the bonded ligand. Hence, anion complexation ability decreases. At the higher concentration of $\mathrm{Cu}(\mathrm{II})(1 \mathrm{~m} M)$, analyte mobility decreased, but peak-broadening and a different elution order 
A

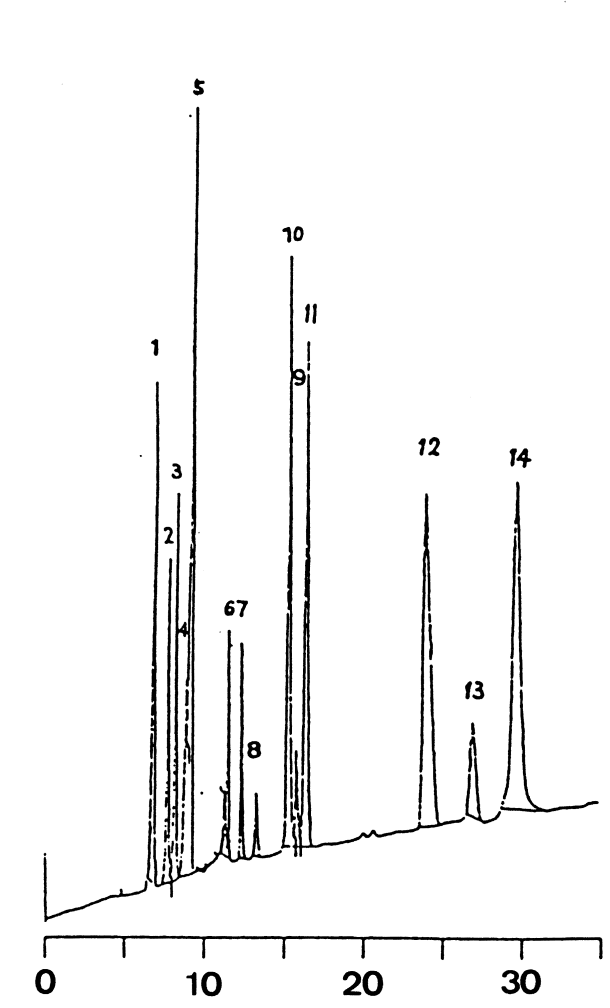

B

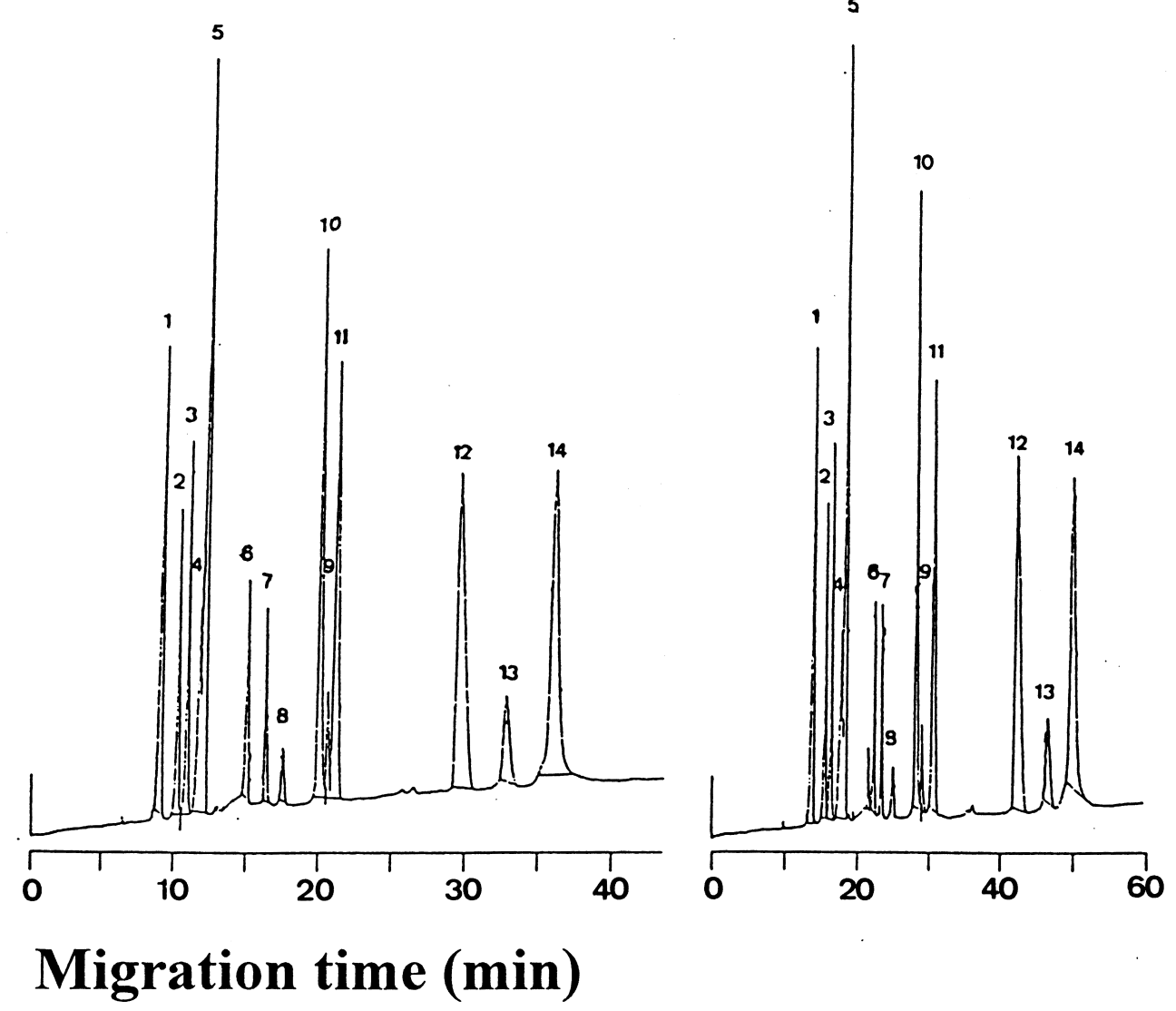

Fig. 8. Effect of applied potential on the separation of aromatic acids. Conditions were the same as in Fig. 6 , except that the background electrolyte was acetate buffer (20 m $M$, pH 4.4). Applied potential: (A) $-20 \mathrm{kV}$; (B) $-15 \mathrm{kV}$; (C) $-10 \mathrm{kV}$. Samples: 1 , pyromellitic acid $(5 \mu M) ; 2$, trimellitic acid $(5 \mu M)$; $3,2,6$-pyridine-dicarboxylic acid (5 $\mu M)$; 4, $o$-phthalic acid $(5 \mu M) ; 5, m$-phthalic acid $(10 \mu M) ; 6, p$-phthalic acid $(10 \mu M) ; 7$, salicylic acid $(10 \mu M) ; 8$, mandelic acid $(10 \mu M) ; 9, p$-sulfanilic acid $(10 \mu M) ; 10$, benzoic acid $(10 \mu M)$; 11, 3-hydroxy-2-naphthoic acid $(2 \mu M) ; 12$, gallic acid $(10 \mu M) ; 13, p$-anisic acid $(10 \mu M) ; 14, p$-hydroxybenzoic acid $(10 \mu M)$. 
were obtained. The higher ionic strength of the background electrolyte can account for this. Copper reduction on the platinum electrode was seen in this case. Nitric acid $(6 M)$ is necessary to remove the surface-adsorbed copper. The addition of zinc acetate at 0.1 and $0.5 \mathrm{~m} M$ produced the same effect as that of copper acetate at $0.1 \mathrm{~m} M$. However, the change was less, due to a lesser degree of complex formation between analyte and zinc ion. Increasing the zinc acetate concentration to $1.0 \mathrm{~m} M$ gave rise to distinctly slower migration of the analyte than under the control conditions. Electrophoretic separation in the presence of zinc acetate is shown in Fig. 9. At the lower concentration of zinc acetate, the migration order for $m$-phthalic acid and $o$-phthalic acid was reversed compared with that under control conditions. At higher concentrations of zinc acetate, however, the migration behavior of a larger number of analytes is effected in a more significant way.

\subsection{Mechanism of separation}

The effectiveness of phase bonding has been determined by the measurement of the EOF, as reported in Ref. [19]. Since the direction of EOF was towards the anode, due to the chemically bonded protonated macrocyclic polyamine, sample injection was from the negative end and detection was at the positive end.

Like most capillary electrophoretic conditions, anions were attracted towards the anode, with those having the highest charge-mass ratio migrating first. It is possible to change the charge-mass ratio of many ions by adjusting the $\mathrm{pH}$ of the buffer medium to affect their ionization and, hence, their electrophoretic mobility. According to charge-mass ratio, the migration order at $\mathrm{pH} 4.5$ might be pyromellitic acid $>p$-phthalic acid $>$ trimellitic acid $>m$-phthalic acid $>2$,6-pyridine dicarboxylic acid $>$ salicylic acid $>$

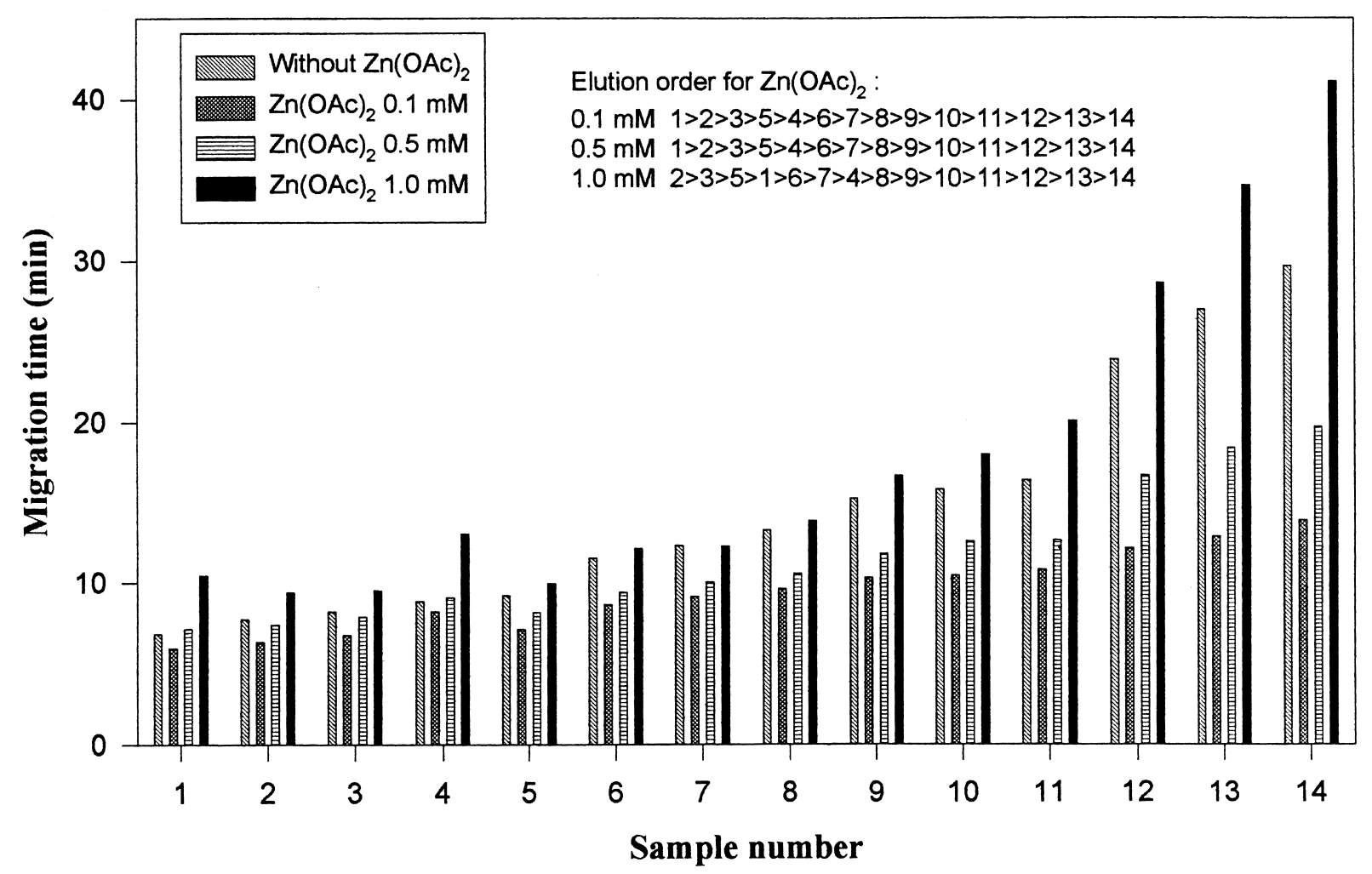

Fig. 9. Electrophoretic separation of aromatic acids on addition of zinc acetate to the background electrolyte. Conditions were the same as in Fig. 6, except that the background electrolyte $(20 \mathrm{~m} M, \mathrm{pH} 4.4)$ contained zinc acetate at (a) $0.1 \mathrm{~m} M$; (b) $0.5 \mathrm{~m} M$ and (c) $1.0 \mathrm{~m} M$. 
$o$-phthalic acid $>$ mandelic acid $>$ benzoic acid $>p$-sulfanilic acid $>$ 3-hydroxy-2-naphthoic acid $>$ gallic acid $>p$-anisic acid $>p$-hydroxybenzoic acid. Unexpectedly, the migration order (Fig. 10) was pyromellitic acid $>$ trimellitic acid $>2$,6-pyridine dicarboxylic acid $>o$-phthalic acid $>m$-phthalic acid $>p$-phthalic acid $>$ salicylic acid $>$ mandelic acid $>$ benzoic acid $>$

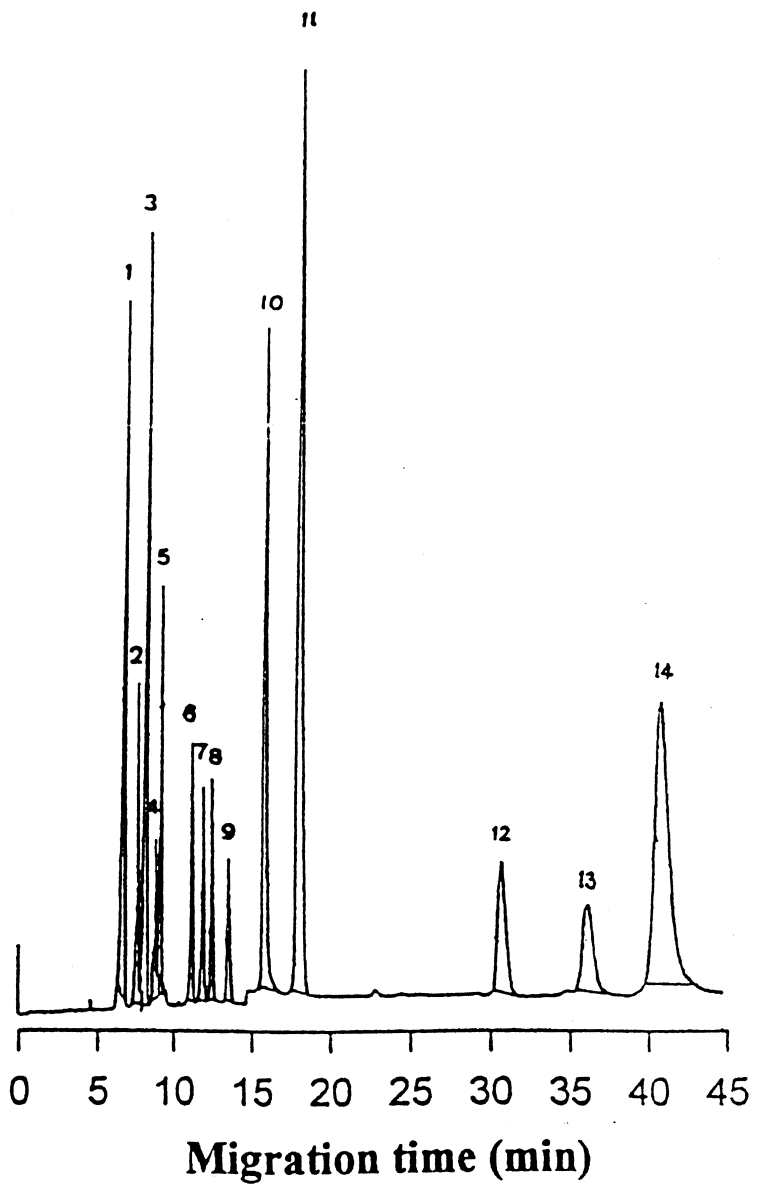

Fig. 10. Electrophoretic separation of aromatic acids. Column, fused silica capillary $(50 \mathrm{~cm} \times 75 \mu \mathrm{m}$ I.D. $)$ with covalent surface modification using macrocyclic polyamine, [28]ane- $\mathrm{N}_{6} \mathrm{O}_{2}$. Sample injection, $3 \mathrm{ml}$ syringe for $2 \mathrm{~s}$. Background electrolyte, acetate (20 $\mathrm{m} M, \mathrm{pH} 4.5)$. Applied voltage, $-20 \mathrm{kV}$. Detection was at $220 \mathrm{~nm}$. Sample concentration, $10 \mu M$ for each, except 3-hydroxy-2naphthoic acid which was $5 \mu M$. Peaks: 1 , pyromellitic acid; 2 , trimellitic acid; 3, 2,6-pyridine-dicarboxylic acid; 4, o-phthalic acid; 5, m-phthalic acid; 6, p-phthalic acid; 7, salicylic acid; 8 , mandelic acid; 9, $p$-sulfanilic acid; 10, benzoic acid; 11, 3hydroxy-2-naphthoic acid; 12, gallic acid; 13, p-anisic acid; 14 , $p$-hydroxybenzoic acid. $p$-sulfanilic acid $>3$-hydroxy-2-naphthoic acid $>$ gallic acid $>p$-anisic acid $>p$-hydroxybenzoic acid. It seems that the charge-mass ratio is not the only factor that is decisive in the separation.

Capillary zone electrophoresis (CZE) is a powerful separation technique for ionic molecules. However, the separation of positional isomers is usually very difficult, because such isomers have the same molecular mass and charge. Wada et al. [23] utilized enhanced ion associability with viologen cations for the separation of naphthalene disulfonates, naphthalene dicarboxylates and phthalate geometrical isomers. Moreover, their results indicated that the separation is not very easy. Only two peaks were observed for the mixture of $o$-phthalic acid, $m$ phthalic acid and $p$-phthalic acid. In this work, three well baseline-resolved peaks were seen for these mixture (Fig. 4B and C). The anion complexation equilibrium might also exert an influence on the separation of geometric isomers of phthalic acid. At $\mathrm{pH} 4.5$, the charge-mass ratio of $p$-phthalic acid is the greatest among these compounds. Moreover, it was the slowest to migrate. Evidently, separations based upon effective charge, equivalent conductance and molecular mass are enhanced by the stationary phase having an anion complexone, which yields shape- and conformation selectivity. The result coincides with the chain-length recognition property of macrocyclic polyamine reported by Lehn et al. [17].

\subsection{Analytical application}

Based on the above results, optimal conditions for the separation of 14 organic acids at the applied potential of $-20 \mathrm{kV}$, with acetate buffer $(20 \mathrm{mM}$, pH 4.5) were selected. As Fig. 10 shows, baseline separation is achieved by using the above-mentioned conditions and a $70-\mathrm{cm}(50 \mathrm{~cm}$ to the detector $) \times 75$ $\mu \mathrm{m}$ I.D. capillary. The separation efficiency was as shown in Table 2. The plate number of the separation efficiency was better than $4 \cdot 10^{4} \mathrm{~m}^{-1}$.

Soy sauce and Salic ointment were sampled and analyzed using the established conditions, except that sample injection was carried out in the electrokinetic mode. Soy sauce was diluted $(1: 500, \mathrm{v} / \mathrm{v})$ prior to the analysis. Salic ointment was dissolved ultrasonically in chloroform-methanol $(1: 1, \mathrm{v} / \mathrm{v})$. The solution was diluted 1:200 $(\mathrm{v} / \mathrm{v})$ prior to the analysis. 
Table 2

Separation efficiency of the bonded-phase capillary column ${ }^{\mathrm{a}}$

\begin{tabular}{|c|c|c|c|c|}
\hline \multirow[t]{2}{*}{ Acid } & \multirow{2}{*}{$\begin{array}{l}\text { Migration } \\
t_{t_{\mathrm{m}}}^{\text {timin }} \\
\text { (min }\end{array}$} & \multicolumn{2}{|c|}{ Separation efficiency } & \multirow{2}{*}{$\begin{array}{l}\text { Resolution } \\
R_{s}{ }^{\mathrm{c}}\end{array}$} \\
\hline & & $N\left(\mathrm{~m}^{-1}\right)^{\mathrm{b}}$ & $H(\mu \mathrm{m})$ & \\
\hline Pyromellitic & 6.80 & 43300 & 23.1 & - \\
\hline Trimellitic & 7.72 & 49300 & 20.3 & 1.65 \\
\hline $\begin{array}{l}\text { 2,6-Pyridine- } \\
\text { dicarboxylic }\end{array}$ & 8.29 & 49300 & 20.3 & 1.32 \\
\hline$o$-Phthalic & 8.93 & 49300 & 20.3 & 1.48 \\
\hline$m$-Phthalic & 9.29 & 49300 & 20.3 & 1.12 \\
\hline$p$-Phthalic & 11.31 & 51800 & 19.3 & 3.65 \\
\hline Salicylic & 12.05 & 49700 & 20.1 & 1.55 \\
\hline Mandelic & 12.59 & 47900 & 20.9 & 1.55 \\
\hline Benzoic & 13.61 & 41600 & 24.0 & 2.00 \\
\hline$p$-Sulfanilic & 15.86 & 46100 & 21.7 & 3.90 \\
\hline 3-Hydroxy- & 18.02 & 46900 & 21.3 & 3.58 \\
\hline 2-naphthoic & & & & \\
\hline Gallic & 30.82 & 46900 & 21.3 & 9.00 \\
\hline$p$-Anisic & 36.30 & 46900 & 21.3 & 2.95 \\
\hline $\begin{array}{l}p \text {-Hydroxy- } \\
\text { benzoic }\end{array}$ & 40.98 & 39900 & 25.0 & 1.95 \\
\hline
\end{tabular}

${ }^{\mathrm{a}}$ Capillary, [28]ane- $\mathrm{N}_{6} \mathrm{O}_{2}$ bonded-phase; column's dimensions, $70 \mathrm{~cm}$ [effective length, $50 \mathrm{~cm}$ ] $\times 75 \mu \mathrm{m}$ I.D.; background electrolyte, acetate buffer (20 mM, pH 4.5); applied potential, $-20 \mathrm{kV}$; sample injection, vacuum ( $2 \mathrm{~s}$ with $3 \mathrm{ml}$ syringe); detection was at $220 \mathrm{~nm}$.

${ }^{\mathrm{b}} N, 5.54\left(t_{\mathrm{m}} / w_{1 / 2}\right)^{2} ; w$ : peak width.

${ }^{\mathrm{c}} R_{s}, \Delta t / w_{\text {ave }}, 2\left(t_{2}-t_{1}\right) /\left(w_{1}+w_{2}\right)$.

The peaks for each analyte were identified by spiking samples with known standards and inspecting the resulting changes. The results are listed in Table 3.

When we analyzed Aspirin, the peak of acetylsalicylic acid was observed at a migration time of $7.8 \mathrm{~min}$. A small peak was also found at $6.5 \mathrm{~min}$. If a freshly prepared sample was stored at $4^{\circ} \mathrm{C}$ for 12 $\mathrm{h}$, the small peak increased in size and that of acetylsalicylic acid decreased. Further incubation of the sample vial in a water bath of $50^{\circ} \mathrm{C}$ for $2 \mathrm{~h}$ led to an equilibrium condition of the hydrolysis of acetylsalicylic acid (Fig. 11). The reproducibility of the migration time for acetylsalicylic acid was $7.88 \pm 0.24 \mathrm{~min}$ (RSD: $\pm 3.02 \%$ ) and for salicylic acid, it was $6.68 \pm 0.20 \mathrm{~min}$ (RSD: $\pm 3.09 \%$ ).

\section{Conclusion}

With the bonded-phase capillary column, reversal of the EOF was seen without the addition of any other modifier. This easier process makes the sensitivity of the detection greater. Fourteen organic acids, including geometric isomers that are very

Table 3

Determination of aromatic acids in real samples using the standard addition method ${ }^{\mathrm{a}}$

\begin{tabular}{lcccc}
\hline Samples & \multicolumn{1}{c}{ Linearity (peak area) } & \multirow{2}{*}{ Amount found } \\
\cline { 2 - 4 } & Slope $(\mu \mathrm{V} / \mu M)$ & Intercept $(\mu \mathrm{V})$ & $r^{2}$ & \\
\hline Benzoic acid in & & & 0.9928 & $500 \mathrm{ppm}$ \\
$\quad$ Doli soy sauce & 379.6 & 2505 & 0.9954 & $290 \mathrm{ppm}$ \\
$\quad$ Kinglan soy sauce & 358.2 & 1707 & 0.9971 & $1.3 \%$ \\
Salicylic acid in & 931.6 & 1745 & & \\
$\quad$ Salic ointment & & & & \\
\hline
\end{tabular}

\footnotetext{
${ }^{a}$ Conditions were the same as in Fig. 10; Soy sauce $(1 / 500, \mathrm{v} / \mathrm{v})$ was diluted with pure water. Salic ointments was dissolved in a mixed solvent of chloroform-methanol $(1: 1, \mathrm{v} / \mathrm{v})$, then diluted to $1: 200(\mathrm{v} / \mathrm{v})$ with pure water.
} 
A

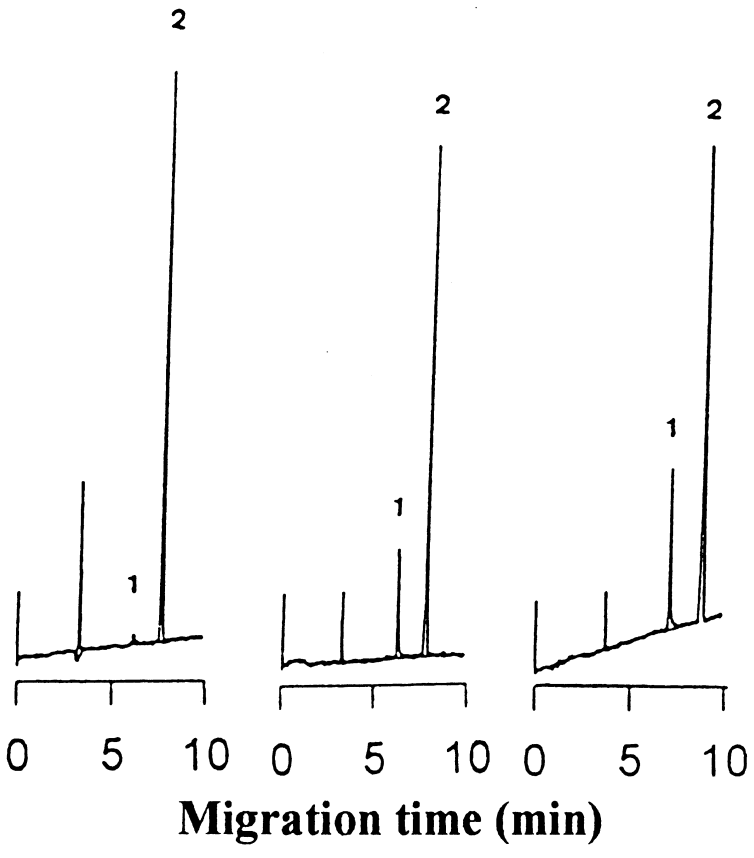

Fig. 11. Analysis of acetylsalicylic acid in an Aspirin tablet. Conditions were the same as in Fig. 10, except that sample injection was by electrokinetic methods $(-10 \mathrm{kV}, 10 \mathrm{~s})$ and acetate buffer was at $30 \mathrm{mM}, \mathrm{pH} 4.5$. Sample, (A) freshly prepared sample solution; (B) sample was kept at $4^{\circ} \mathrm{C}$ for $12 \mathrm{~h}$; (C) sample was kept in a water bath at $50^{\circ} \mathrm{C}$ for $2 \mathrm{~h}$. Peaks: 1, salicylic acid; 2, acetylsalicylic acid.

similar in ionic mobility, were well-resolved in acetate buffer, whereas only 13 peaks were observed in phosphate buffer, even in the presence of organic solvent. This indicates that the buffer's anion affects selectivity under the present experimental conditions. Most of the data confirm the assumption that the selectivity of the system is based mainly on anion complexation behavior. The separation efficiency (both theoretical plate number and resolution) for aromatic organic anions is much better than that for the inorganic anions shown in the previous paper [19]. In this work, the phenomena of electrophoresis and anion complexation in the bonded-phase act in concert but to varying degrees, just as those found in many works relating electrophoresis and dynamic cation complexation [24-27] or guest-host complexation [28]. Such multifunctional binding should lead to even more selective separation and warrants further investigation into the factors that control the migration behavior.

\section{Acknowledgements}

The authors thank the National Science Council of Taiwan for financial support.

\section{References}

[1] J. Chen, B.P. Preston, M.J. Zimmerman, J. Chromatogr. A 781 (1997) 205.

[2] X. Huang, J.A. Luckey, M.J. Gordon, R.N. Zare, Anal. Chem. 61 (1989) 766.

[3] T. Tsuda, J. High Resolut. Chromatogr. Chromatogr. Commun. 10 (1987) 622.

[4] M. Chiari, N. Dell'Orto, L. Casella, J. Chromatogr. A 745 (1996) 93.

[5] T. Takayanagi, E. Wada, S. Motomizu, Analyst 122 (1997) 1387.

[6] Y. Liu, D.J. Pietrzyk, J. Chromatogr. A 804 (1998) 337.

[7] M.M. Hsieh, H.T. Chang, J. Chromatogr. A 793 (1998) 145.

[8] K. Sarmini, E. Kenndler, J. Chromatogr. A 811 (1998) 201.

[9] K. Sarmini, E. Kenndler, J. Chromatogr. A 818 (1998) 209.

[10] J.H. Knox, K.A. McCormack, Chromatographia 38 (1994) 279.

[11] L.A. Colon, Y. Guo, A. Fermier, Anal. Chem. 69 (1997) 461A.

[12] A.L. Crego, A. Gonzalez, M.L. Marina, Crit. Rev. Anal. Chem. 26 (1996) 261.

[13] A.S. Rathore, C. Horvath, J. Chromatogr. A 743 (1996) 231.

[14] M.G. Cikalo, K.D. Bartle, M.M. Robson, P. Myers, M.R. Euerby, Analyst 123 (1998) 87R.

[15] K.D. Altria, I. Grant, LC·GC Int. 11 (1998) 588.

[16] J.M. Lehn, Angew. Chem. Int. Ed. Engl. 27 (1988) 89.

[17] J.M. Lehn, R. Meric, J.P. Vigneron, I. Bkouche-Waksman, C. Pascard, J. Chem. Soc. Chem. Commun. (1991) 62.

[18] J.C. Hsu, W.H. Chen, C.Y. Liu, Analyst 122 (1997) 1393.

[19] C.Y. Liu, W.H. Chen, J. Chromatogr. A 815 (1998) 251.

[20] S.D. Chyueh, C.Y. Liu, Fresenius' J. Anal. Chem. 354 (1996) 278.

[21] C.F. Yeh, S.D. Chyueh, W.S. Chen, J.D. Fan, C.Y. Liu, J. Chromatogr. 630 (1993) 275.

[22] C.Y. Liu, C.C. Hu, C.L. Yang, J. Chromatogr. A 773 (1997) 199.

[23] E. Wada, T. Takayanagi, S. Motomizu, Analyst 123 (1998) 493.

[24] F.B. Erim, A.S. Kezban, Fresenius' J. Anal. Chem. 362 (1998) 418.

[25] M. Macka, P. Nesterenko, P.R. Haddad, J. Microcol. Sep. 11 (1991) 1 . 
[26] M.T. Bowser, D.D.Y. Chen, Electrophoresis 19 (1998) 383.

[27] N.E. Ballou, G.R. Ducatte, C. Quang, V.T. Remcho, J. High Resolut. Chromatogr. 19 (1996) 183.

[28] X. Peng, M.T. Bowser, P. Britz-McKibbin, G.M. Bebault, J.R. Morris, D.D.Y. Chen, Electrophoresis 18 (1997) 706.
[29] R.M. Smith, A.E. Martel, Critical Stability Constants, Plenum Press, New York, 1976.

[30] J.A. Dean, Lange's Handbook of Chemistry, McGraw-Hill, New York, 1985. 